\title{
How to See the Future FORECASTING AND GLOBAL POLICY
}

September 27-28, 2021 


\section{ABOUT PERRY WORLD HOUSE}

Perry World House is a center for scholarly inquiry, teaching, research, international exchange, policy engagement, and public outreach on pressing global issues.

Perry World House's mission is to bring the academic knowledge of the University of Pennsylvania to bear on the world's most pressing global policy challenges and to foster international policy engagement within and beyond the Penn community.

Located in the heart of campus at 38th Street and Locust Walk, Perry World House draws on the expertise of Penn's 12 schools and numerous globally oriented research centers to educate the Penn community and prepare students to be well-informed, contributing global citizens. At the same time, Perry World House connects Penn with leading policy experts from around the world to develop and advance innovative policy proposals.

Through its rich programming, Perry World House facilitates critical conversations about global policy challenges and fosters interdisciplinary research on these topics. It presents workshops and colloquia, welcomes distinguished visitors, and produces content for global audiences and policy leaders, so that the knowledge developed at Penn can make an immediate impact around the world.

The 2021 Global Order Colloquium is made possible by the generous support of Carnegie Corporation of New York; The Elliott and Harriet Goldstein Private Foundation and Jesse Friedlander; and Paritosh V. Thakore (W'86) and Hemal Mirani (G'97, WG'97). 
REPORT AUTHORS

Breanna Moore

Ph.D. Candidate, History,

University of Pennsylvania

Jared Rosen

Research Fellow, Perry World House

\section{Christian Ruhl}

Global Order Program Manager,

Perry World House

\section{INTRODUCTION: BETTER FORECASTS MEAN BETTER POLICY}

BACKGROUND: FORECASTING AT PENN

AND PERRY WORLD HOUSE 6

8 DAY ONE (SEPTEMBER 27)

9 MORGAN MUIR

BREAKING NEWS 9

"BLENDING MACHINE-BASED ANALYSIS WITH EXPERTISE"............ 9

A MORE CONTESTED WORLD ................................................................. 10

\section{GLOBAL ECONOMY}

LEARNING FROM FAILURES OF PREDICTION. . .12

FORECASTING THE

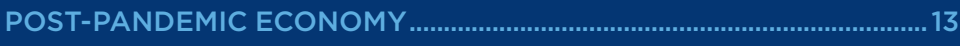

PREDICTIVE POWERS OF THE MARKET ................................................. 14

\section{NATIONAL SECURITY}

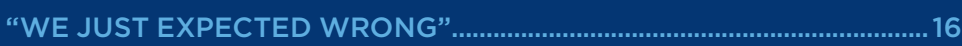

THE CLIMATE CHALLENGE .......................................................................17

CAPTURING THE SPILLOVER EFFECTS OF

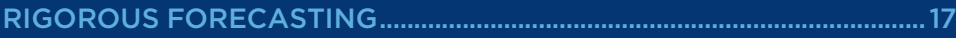

ALLIES, ADVERSARIES, AND INTEGRATING

FOREIGN AND DOMESTIC POLICY

\section{GLOBAL HEALTH}

FORECAST ACCURACY: THE WRONG PROBLEM? ...............................20

FORECAST COMMUNICATION............................................................... 21

PRIORITIZING PROBLEMS THROUGH BETTER FORECASTING......... 23

\section{DAY TWO (SEPTEMBER 28)}

\section{ELLEN JOHNSON SIRLEAF}

COVID-19 AND VACCINE INEQUITY ............................................................. 25

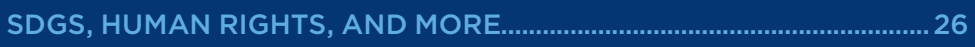

PENN AND WEST AFRICA ................................................................ 26

\section{BEN RHODES}

THE CHALLENGE OF GLOBAL AUTHORITARIANISM .......................... 27

"BETTER THAN 50 PERCENT CHANCE" .................................................... 28

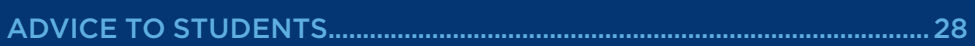

\section{NEXT STEPS}

POLICY AND RESEARCH RECOMMENDATIONS ..................................... 29

INCREASING BUREAUCRATIC DEMAND FOR FORECASTING........... 30

LEARNING FROM ALLIES-AND ADVERSARIES........................................ 30

ROADMAPS TO PERMANENT FORECASTING IMPLEMENTATION.... 31

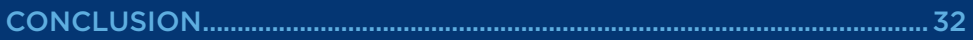

WHAT THE EXPERTS ARE READING ......................................................... 33 


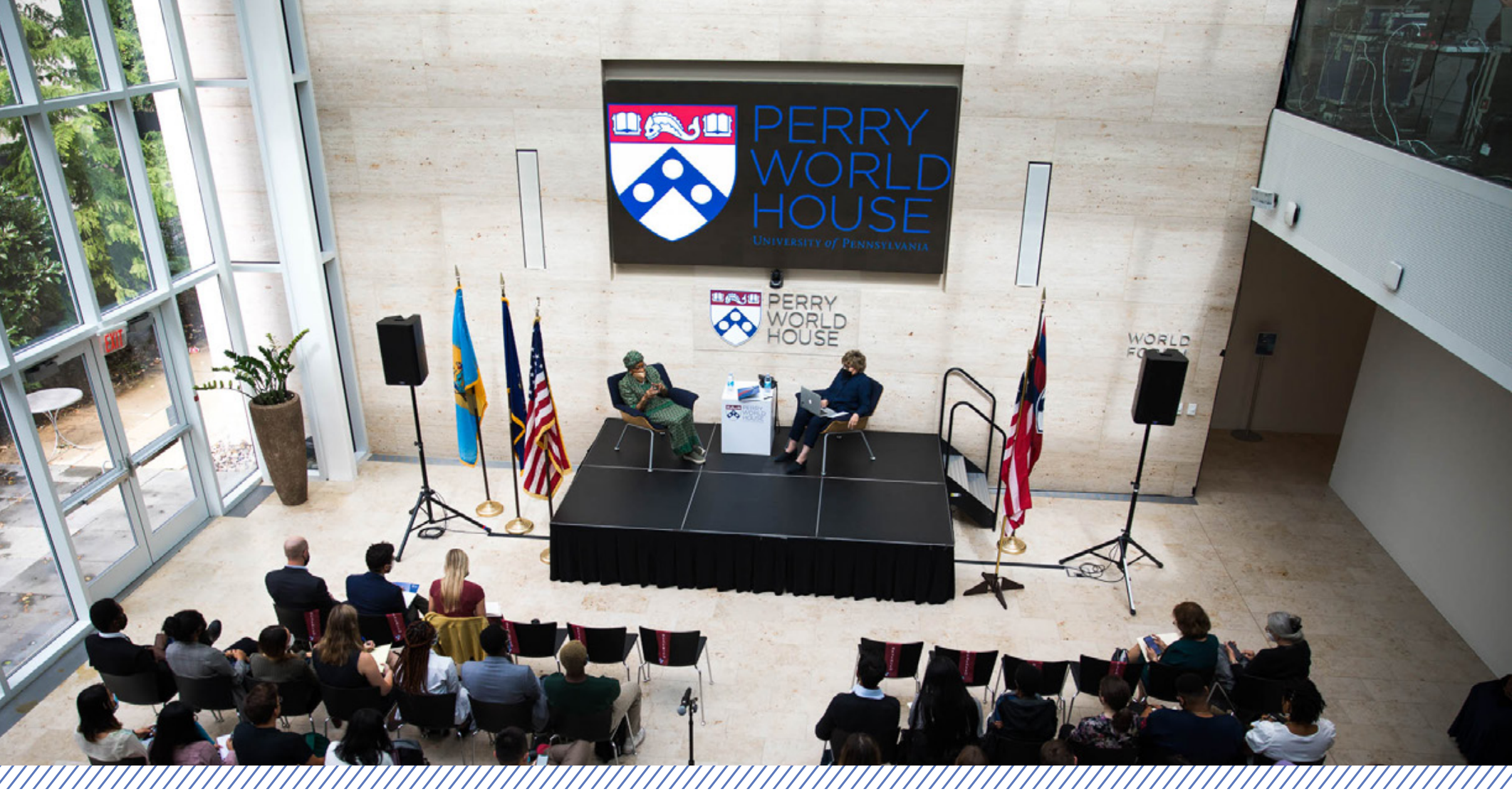

Former President of Liberia Ellen Johnson Sirleafin conversation with NPR's Deborah Amos at Perry World House.

INTRODUCTION

\section{\BETTER FORECASTS MEAN BETTER POLICY}

There is a gap between academic research and policy application in forecasting methods. Scholarship and experiments have shown that new methods-especially crowdsourced probabilistic forecasting-can significantly improve forecast accuracy, but the world's governments, including the United States, have mostly failed to implement these new methods and integrate them with existing tools for predicting the future. The gap has been especially visible recently, given questions about whether the U.S. government accurately forecasted the timeline of the Taliban's reconquest of Afghanistan, the world's failure to prepare for the COVID-19 pandemic, and economists' and firms' inability to foresee the collapse of the Chinese real estate giant Evergrande. On each of the issues-national security, global health, and the global economy-could better forecasting tools have led to better outcomes? 
To help bridge this gap and advance discussions on forecasting, Perry World House convened a two-day colloquium focused on "How to See the Future: Forecasting and Global Policy" on September 27-28, 2021. The colloquium was animated by a simple belief: Better forecasts can facilitate better policy. When governments can rank the probabilities of global threats, when they can understand the factors that increase the likelihood of a global pandemic or a terrorist attack, and when they can have more accurate information about their adversaries' likely actions, they can tailor policy more accurately to the world's most pressing problems.

To facilitate new insights on forecasting and global policy, Perry World House launched the colloquium with an interdisciplinary approach, exchanging insights on various techniques-including common techniques in economics, epidemiology, machine-learning-assisted forecasting models, prediction markets and forecasting aggregation platforms, war-gaming, scenario analysis, and more-and identifying synergies between them. In line with the mission of Perry World House and its grant from Carnegie Corporation of New York, the colloquium bridged the gap between academia and the policy world by putting top scholars in direct conversation with practitioners, where policymakers can describe their greatest challenges and scholars can offer their most powerful analytical tools. In short, the colloquium sought to answer one big question from several angles: How can we better see the future? More specifically, what forecasting methods are promising but neglected, how can these methods be implemented, how can forecasts be better communicated, and how can they be made most useful to policymakers?

The colloquium included a workshop and three public keynotes. The workshop brought together top academics, current and former government officials from the United States and abroad, industry representatives, and others for high-level discussionsin a hybrid format, both on Zoom and in person at Perry World House in Philadelphia. The three keynotes helped fulfill Perry World House's goal of "bringing the world to Penn" as students, faculty, staff, and members of the public heard expert insights from Morgan Muir, the U.S. Deputy Director of National Intelligence for Mission Integration; Ellen Johnson Sirleaf, the former President of Liberia and recipient of the Nobel Peace Prize; and Ben Rhodes, a former Senior Advisor to President Barack Obama and the former U.S. Deputy National Security Advisor.
This report details the results of the two days of discussions. After the following section introducing and providing background to forecasting at Perry World House, the report discusses each of the colloquium's keynotes and workshop panels. A final section makes recommendations in three broad categories to drive forward the momentum in forecasting:

\section{Increasing bureaucratic demand for forecasting: crowdsourced forecasting only succeeds when the crowd forecasts, and when analysts and policymakers alike view probabilistic forecasts as a valuable tool, not an obligation.}

\section{Learning from allies-and adversaries: The United Kingdom's COSMIC BAZAAR program provides a model for success for other nations, including the United States. Innovation in forecasting, moreover, could be a key advantage in great power competition.}

\section{A roadmap to permanent forecasting implementation: In order to succeed, a new forecasting platform must be implemented strategically, such that it becomes a permanent- and inextricable-feature of the intelligence and policy processes.}




\section{BACKGROUND: FORECASTING AT PENN AND PERRY WORLD HOUSE}

The University of Pennsylvania has a history of developing innovative forecasting methods. The research of Professor Barbara Mellers, Professor Philip Tetlock, and others at Penn has shown the fallibility of experts, the importance of cognitive biases, and the relevance of the wisdom of the crowds in predicting future geopolitical events. This research gained prominence in the 2010s during forecasting tournaments sponsored by the U.S. intelligence community through the Intelligence Advanced Research Projects Activity (IARPA). In IARPA's Aggregative Contingent Estimation program, a Penn-led research team known as the Good Judgment Project demonstrated that crowdsourced forecasting, debiasing, and other practices could help optimize the performance of forecasting teams and identify "superforecasters," individuals with exceptional abilities to make probabilistic forecasts.

The intelligence community, which has experimented with prediction markets and forecasting tournaments since the early 2000s, took note that Good Judgment forecasters outperformed even analysts with access to classified information, and launched a series of initiatives designed to harness the wisdom of crowds and the power of markets to better predict geopolitical events. Since then, however, progress in the adoption of probabilistic forecasting methods within the U.S. government has stalled, and, in recent years, several initiatives ended. ${ }^{1}$ (Reversing this trend, Morgan Muir announced on the first day of the colloquium that the National Intelligence Council was planning to launch new probabilistic forecasting initiatives, as discussed below.)
Earlier this year, Perry World House published a new white paper on crowdsourced probabilistic forecasting, Keeping Score: A New Approach to Geopolitical Forecasting. ${ }^{2}$ The paper outlined the evidence base for forecasting research, discussed reasons for the adoption failures of forecasting methods in government, and made recommendations for how such methods can be improved and strategically implemented so that they find a permanent home and survive changing political and bureaucratic winds. This work was supported in part by Open Philanthropy. A shorter piece, "How the U.S. Government Can Learn to See the Future," followed in Lawfare. ${ }^{3}$ Perry World House also launched the Predictive Intelligence Assessments Methods (PRIAM) working group, convening policymakers, scholars, and industry leaders to discuss ways of implementing and improving forecasting in government. Named after the Trojan King Priam of Greek mythology, whose daughter Cassandra could see the future but was cursed never to be believed, PRIAM has continued to advance discussions in forecasting at Penn, again made possible in part with the support of Open Philanthropy. Perry World House has continued research into the implementation of these forecasting methods, including through structured interviews of policymakers. This colloquium is complementary to these efforts, exploring the lessons different fields can provide for seeing the future more clearly.

As part of the colloquium, Perry World House asked participants to fill out a short survey on forecasting methods, the probabilities of various world events, and more. The charts in this report are based on participants' responses. Not all panelists answered all questions, and these charts should not be interpreted to represent any individual panelist's view. Additionally, the discussions of the workshop panels (National Security, Global Health, the Global Economy) were held under a non-attribution rule. Quotations have therefore been anonymized and should not be attributed to specific speakers. Any attributed quotations have been taken from written analyses that participants contributed to the workshop.

\footnotetext{
A notable exception to this trend can be found outside the United States, in the United Kingdom's COSMIC BAZAAR program.

Michael C. Horowitz, Julia Ciocca, Lauren Kahn, and Christian Ruhl, Keeping Score: A New Approach to Geopolitical Forecasting, Perry World House, 2021, https://global.upenn.edu/sites/default/files/perry-world-house/Keeping\%20Score\%20Forecasting\%20White\%20Paper.pdf.

3 Michael C. Horowitz, Julia Ciocca, Lauren Kahn, and Christian Ruhl, "How the U.S. Government Can Learn to See the Future," Lawfare, 2021, https://www. lawfareblog.com/how-us-government-can-learn-see-future.
} 


\section{WORKSHOP PARTICIPANT FORECASTS}

In the pre-workshop survey, Perry World House asked panelists to forecast the probabilities of various world events. The table below outlines the average probability of the participants' forecasts for each event.

\section{FORECASTING QUESTION}

\section{Another Pandemic}

What is the likelihood of another global pandemic either through a resurgence of COVID-19 or one of its variants, or through a novel disease, over the next five years?

\section{ASAT Weapons}

What is the probability that a state will use anti-satellite (ASAT) weapons against another state's space assets over the next five years?

\section{Biden Second Term}

What is the probability that President Joe Biden will begin a second term in January 2025?

\section{U.S.-China Clash}

What is the likelihood of a military confrontation between the United States and China that results in at least one death over the next five years?

\section{Paris Climate Targets}

What is the likelihood that the largest emitters will be on track to reduce their greenhouse gas emissions by the Paris targets in five years?

\section{Cyber Article 5}

What is the likelihood that NATO will invoke Article 5 in response to a cyberattack on one of its member states over the next five years?

\section{$<1.5^{\circ}$ Warming}

By 2030, what is the probability that global emissions can be reduced such that global temperatures will not increase beyond 1.5 degrees Celsius?

\section{AVERAGE FORECASTED PROBABILITY}

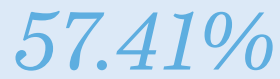

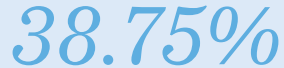

$38.21 \%$
$21.56 \%$
$21.88 \%$

$18.13 \%$ 
> DAY ONE (SEPTEMBER 27) 
KEYNOTE

\section{$>$ MORGAN MUIR}

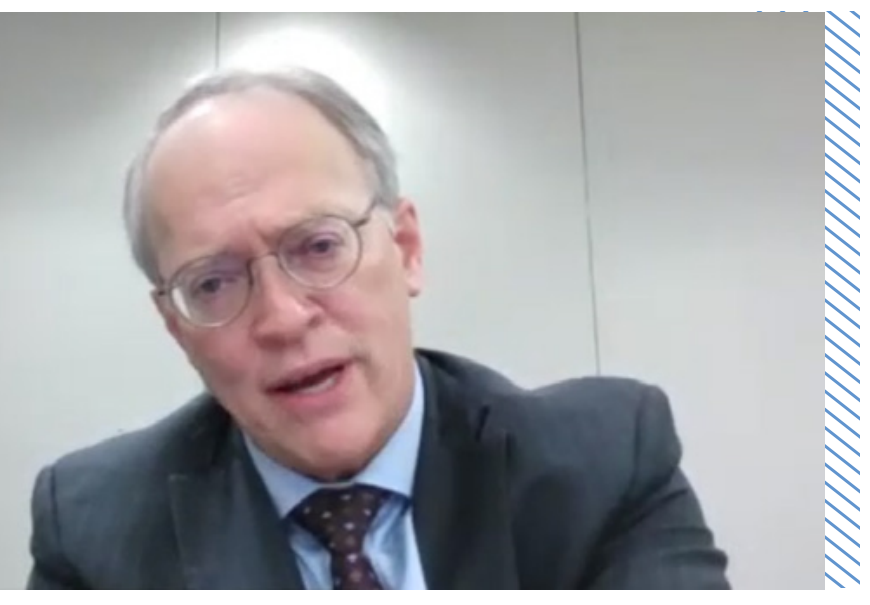

Morgan Muir, U.S. Deputy Director of National Intelligence for Mission Integration.

The first day of the colloquium brought together scholars and practitioners from around the world for three closed-door expert discussions and one public keynote conversation. In the morning, Morgan Muir, U.S. Deputy Director of National Intelligence for Mission Integration, gave a keynote speech on "The Future of the World: Forecasting and the U.S. Intelligence Community," and engaged in a wide-ranging conversation with Michael C. Horowitz, the Richard Perry Professor at Penn and Director of Perry World House, discussing the U.S. intelligence community's methods for understanding future trends and the value of probabilistic forecasting, among other topics.

\section{BREAKING NEWS}

During the conversation, Muir broke the news that a new crowdsourced forecasting initiative is launching in the intelligence community. "We are exploring right now efforts to move along these paths," he said. "We are incorporating some of the insights that we've gotten from years past and in the academic literature now into a new crowdsourced forecasting tool designed to be inclusive, open, and responsive to both analyst and policymaker desire for transparency and relevance. The NIC [National Intelligence Council] has established a new position focused on forecasting, and I know that the CIA is planning a new forecasting workshop focused on probabilistic thinking methods. In addition, the IC's [intelligence community's] move to the cloud has allowed for a more technical infrastructure there to pursue efforts-how do we augment human analysis and expert judgment with machine learning?-allowing us to make better sense of the data that we have as well as sort of the modeling that's going on." Perry World House had recommended the re-implementation of crowdsourced probabilistic forecasting tools earlier this year in Keeping Score.

\section{"BLENDING MACHINE-BASED ANALYSIS WITH EXPERTISE"}

Part of the challenge the intelligence community faces is that data collection has, to an extent, outpaced data analysis—or, as Muir put it, "the data has exploded." Technological innovations in data analytics and the intelligence community' approach to data mining will help to analyze these data and use them to make more accurate predictions about the future, but organizational changes, too, will be necessary to create better humanmachine interactions.

"The key thing [is that] the tools have to work for the analyst, and they have to better serve the policymakers," Muir said. "We need to figure out how to demonstrate to the analysts and to the policymakers the benefits of blending machine-based analysis with expertise and ways that can address anomalies, inconsistencies, and uncertainties and deliver that insight at speed." Pairing human expert judgment and individual or crowdsourced forecasts with machine learning can allow governments to make new insights, at greater scale and with greater speed than was possible before. 


\section{A MORE CONTESTED WORLD}

The latest Global Trends report from the Office of the Director of National Intelligence was called A More Contested World. ${ }^{4}$ Muir explained to the audience the process of how these reports are produced every four years with the aim of looking 20 years into the future. Key takeaways from the report included that, in Muir's words, "shared global challenges are becoming more frequent and intense." He highlighted how such transnational challenges can interact in complex ways, where climate change, global health, and other global challenges and fragmentation begin to strain existing institutions.

In part, this has led to "a widespread dissatisfaction with existing governing models." A key question for the future, therefore, will be how these existing models can adapt to face the challenges of the coming years and how they can help to deliver better services in all kinds of societies. In the meantime, a wave of protest movements has swept the globe in every kind of system, from liberal democracy to closed authoritarian states. Who can answer these challenges will help to determine who will shape the course of the coming years.

Nonetheless, a "more contested world" is not necessarily a bad thing, and as Muir said, "The contest of ideas is the foundation of democracy and an opportunity for reforms and advancement." Contestation can lead to innovation, and the spirited exchange of ideas - as the workshop panels that followed Muir's keynote illustrated - can create fresh insights and deeper understanding of critical issues.

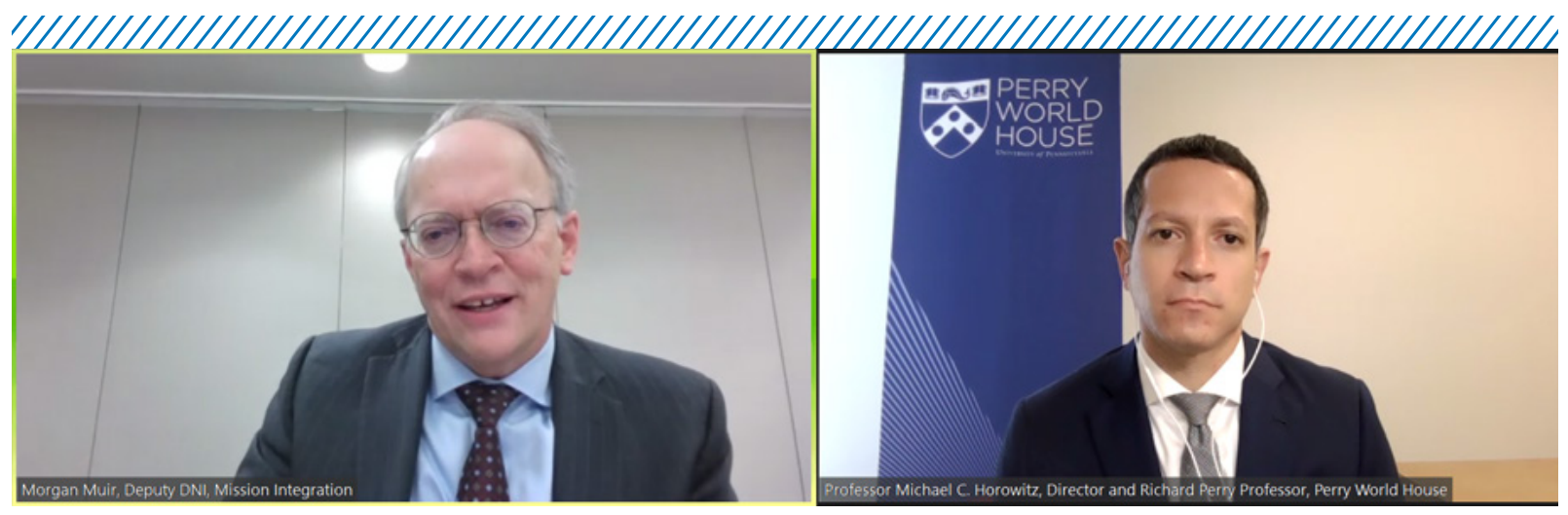

Morgan Muir in conversation with Perry World House Director Michael C. Horowitz.

\title{
"We are incorporating some of the insights that we've gotten ... into a new crowdsourced forecasting tool designed to be inclusive, open, and responsive to both analyst and policymaker desire for transparency and relevance."
}

\author{
-Morgan Muir, Deputy DNI for Mission Integration
}


WORKSHOP

\section{$>$ GLOBAL ECONOMY}

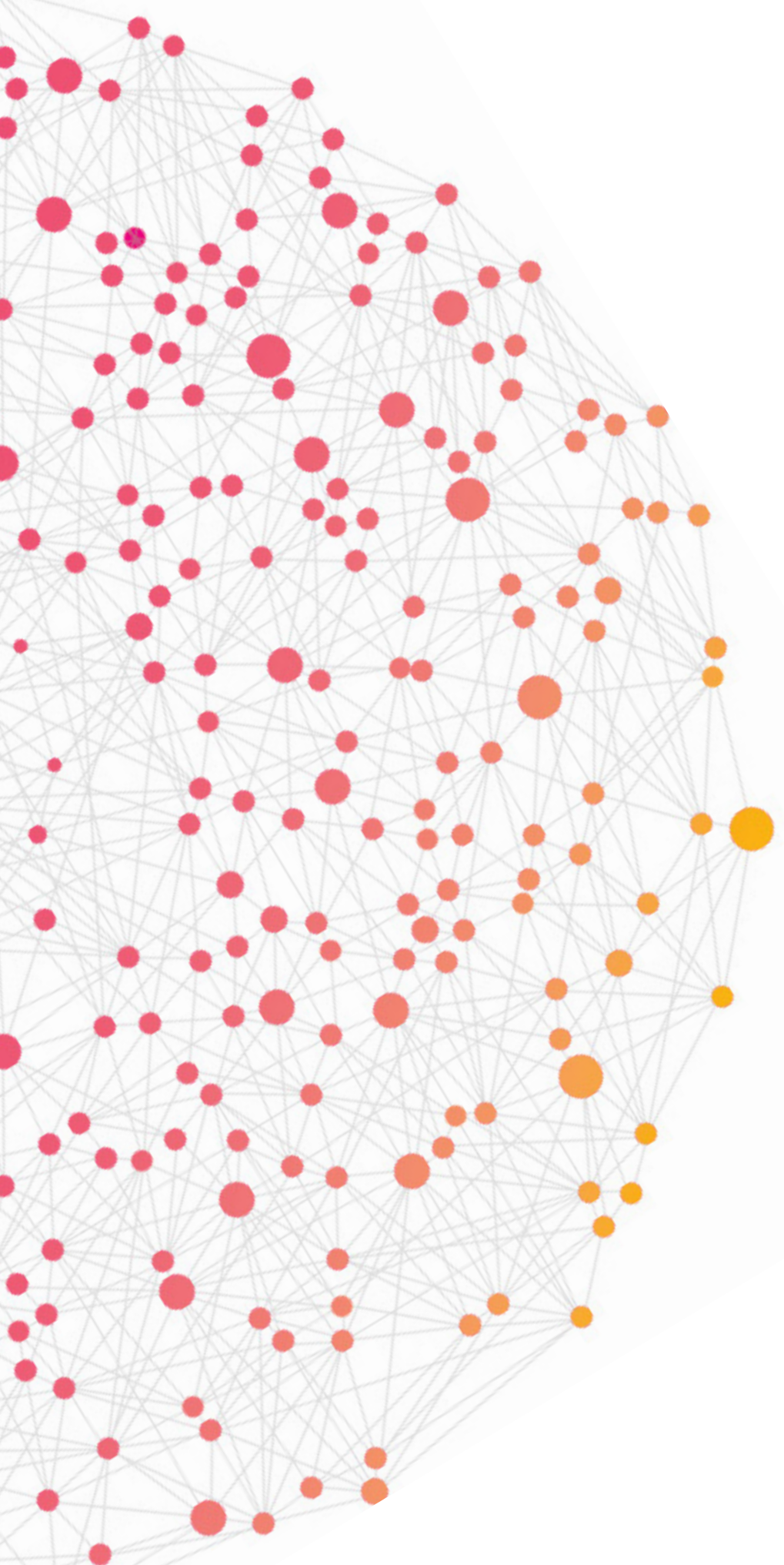

After Muir's public keynote, the first closed-door workshop panel focused on the global economy and forecasting trends and developments in economics and business. Moderating the panel was Witold Henisz, the Deloitte \& Touche Professor of Management in honor of Russel E. Palmer, the Director of the Political Risk Lab, and the Founder of the Environmental, Social, and Governance Analytics Lab at Penn's Wharton School. Panelists included Agathe Demarais, the Global Forecasting Director at The Economist Intelligence Unit; Ana Beatriz Galvao, a Professor of Economic Modeling and Forecasting at the Warwick Business School; Mark Rosenberg, the CEO of GeoQuant; and Eric Zitzewitz, a Professor of Economics at Dartmouth College. The panelists touched on the challenges of forecasting global economic trends, the strengths of different forecasting methods, as well as their predictions for the future. 

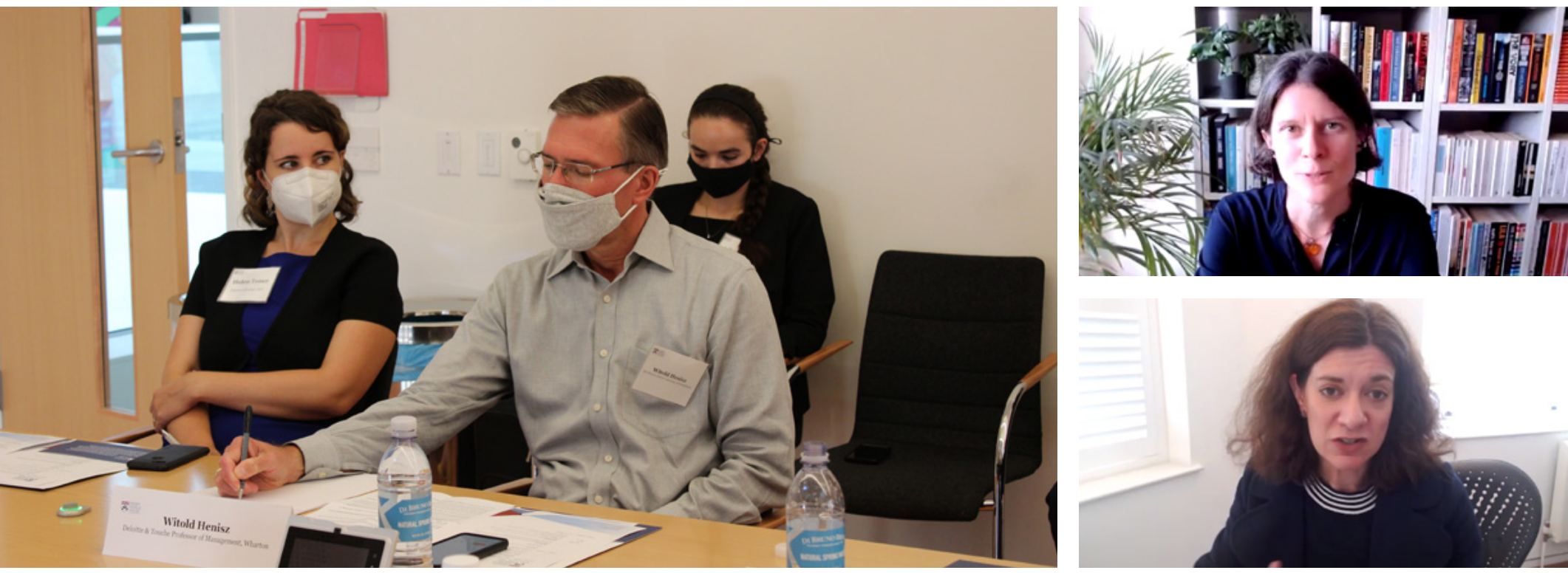

This conversation included contributions from (left-to-right) Helen Toner, Director of Strategy at Georgetown University's Center for Security and Emerging Technology; Witold Henisz, Deloitte \& Touche Professor of Management at the University of Pennsylvania; Agathe Demarais, Global Forecasting Director at the Economist Intelligence Unit; and Ana Beatriz Galvão, Professor of Economic Modeling and Forecasting at the Warwick Business School.

\section{LEARNING FROM FAILURES OF PREDICTION}

At the outset of the COVID-19 pandemic, some pundits predicted economic disaster. This prediction, however, has largely failed to pass; in spite of supply-chain disruptions, a prolonged period of high unemployment, and the horrific human costs of the pandemic around the world, the global economy is far from collapse. Nonetheless, the pandemic seems likely to leave lasting effects. As Agathe Demarais noted in her written contribution to the workshop, based on an Economist Intelligence Unit model, "Those countries that will vaccinate less than 60 percent of their population by mid-2022 will register GDP losses totaling US\$2.3trn in 2022-25 (roughly equivalent to the annual GDP of France). Emerging countries will shoulder around two-thirds of these losses, further delaying their economic convergence with more developed countries." Like Demarais' contribution, the panel focused on big questions about the global economy: How can forecasts about the global economy be made more accurate, especially in light of the uncertainties of COVID-19? What lessons do prediction markets hold for economic forecasters, and what are the limits of these tools? And what practices from economic forecasting can improve forecasts in other realms of global policy?

At heart, much economic policy is a forecasting exercise, which relies on models of the economy and predictions on how various interventions may influence economic systems and actors. Indeed, economics has long been an incubator of cutting-edge forecasting research, and the logic of prediction markets and forecasting aggregation platforms relies on research from the discipline. Yet even here, the track record is mixed. The Bureau of Labor Statistics' (BLS) decade-long employment forecasts, for example, are fascinating but unreliable. As one observer noted at the release of the 2012-2022 projections, "Every decade, the BLS makes these predictions, and every decade, the BLS is wrong."

Sources for such forecasts abound. Like national governments, international organizations, too, regularly produce economic forecasts, like the Organisation for Economic Co-operation and Development's Economic Outlook. ${ }^{6}$ The private sector also has strong profit motives to better predict the future of the world. Even in other realms, including global health and national security, the methods of successful private firms may hold useful lessons for scholars and policymakers alike. Unlike pundits, who rarely have to put their money where their mouths are, the fortunes of these firms ride on the success of (sometimes very large) bets about the future.

Despite the commonness of forecasts about the global economy, however, the public has little faith in these forecasts; surveys routinely find that people have low confidence in the profession's ability to predict the future. ${ }^{7}$ As economists themselves are often first to point out, "When an economist tells you something that is based on a theory or a model, you should be very, very skeptical. And the more complicated the theory or model is, the more you should be suspicious."

\footnotetext{
Derek Thompson, "The Government Is Horrible at Predictions (So Is Everybody Else)," The Atlantic, December 20, 2013, https://www.theatlantic.com/ business/archive/2013/12/the-government-is-horrible-at-predictions-so-is-everybody-else/282558/.

6 Organisation for Economic Co-operation and Development, OECD Economic Outlook, Interim Report: Keeping the Recovery on Track, September 2021, https:// www.oecd.org/economic-outlook/.

Noah Smith, "Should We Trust Economists?" The Atlantic, June 4, 2013, https://www.theatlantic.com/business/archive/2013/06/should-we-trusteconomists/276497/.
} 
stimulus money deployed during the pandemic completely surprised many economic modelers-they had predicted the economy well, but not the shifting political possibilities of economic policy.

Other discussions touched on how global debt has grown during the pandemic as states struggled to fix contracting economies and to adjust for troubles in global supply chains. This information was extremely relevant considering the current U.S. national debt-limit crisis. Predicting the probability of sovereign debt crises, some country models can link sovereign debt with economic conditions and interlinkages across countries. Currently, interest rates are low and inflation rates are high within the United States and the United Kingdom. Some participants predicted that central banks will have to raise interest rates to keep inflation stable within the next year and found that the probability of a global downturn in five years and a widespread sovereign debt default crisis is 10 percent higher than usual. Much of the conversation also focused on how different models are suited to different scenarios. Short-term models are useful for tracking current economic conditions but fail to capture new and evolving financial trajectories, while macro-forecasting statistical models with economic theory are better for long-term forecasting and are helpful for storytelling.

\section{PREDICTIVE POWERS OF THE MARKET}

As in national security, prediction markets offer one path to increased accuracy and rigor in economic forecasting. In addition to creating more accurate forecasts, prediction markets can also create a feedback loop for models and theories, crucial in a field based on modeling. As the National Bureau of Economic Research's Erik Snowberg, Justin Wolfers, and Eric Zitzewitz have written, "The real promise of prediction markets comes not from their ability to predict particular events. Rather, the real promise lies in using these markets, often several at a time, to test particular economic models, and use these models to improve economic forecasts." ${ }^{\prime 9}$ Forecasting is not just about creating accurate predictions, but about creating testable models.
Panelists were divided on how and when prediction markets should be used. Several participants pointed out that markets' strengths were in their short-term applications. Prediction-market-based forecasts easily fail when they try to look more long term. Liquidity, too, remains an issue for prediction markets. This is especially true over the long term, as one participant pointed out; it is hard to maintain liquidity for long-term issues over an extended period of time, but short-term issues make it much easier to maintain liquidity. In part, this has a simple explanation: Humans easily lose interest. However, the participant maintained that prediction markets can still be used in the long term.

Here, too, there is room for collaboration among disciplines, and among academia, industry, and government. Corporate prediction markets, for example, face similar challenges as intelligence-community prediction platforms, including, "thinness, weak incentives, limited entry, and the potential for traders with biases or ulterior motives." ${ }^{10}$ Economists' descriptions of corporate prediction platforms (e.g., If markets are run on topics of strategic importance, there is often a need to limit participation for confidentiality reasons) apply just as well to government forecasts on classified topics. ${ }^{11}$ Successful prediction platforms, perhaps especially from firms with corporate cultures similar to that of the IC, might serve as models for government-based probabilistic forecasting initiatives in national security, the subject of the following section.

(?)

\section{QUESTIONS FOR FURTHER RESEARCH}

How can machine-learning-based predictions be made more explainable and be communicated to forecast consumers with little training in computer science?

How can economic models incorporate economic policy and shifting political priorities more accurately, especially during fast-moving crises like COVID-19?

How can short-term prediction-market methods be integrated more seamlessly with longer-term trend forecasts about the economy?

9 Erik Snowberg, Justin Wolfers, and Eric Zitzewitz, "Prediction Markets for Economic Forecasting," National Bureau of Economic Research, July 2012, 35 , https://www.nber.org/system/files/working_papers/w18222/w18222.pdf.

10 Bo Cowgill and Eric Zitzewitz, “Corporate Prediction Markets: Evidence from Google, Ford, and Firm X,” The Review of Economic Studies, 82(4): 1309, October 2015, https://academic.oup.com/restud/article/82/4/1309/2607345.

11 Ibid., 1309-1310. 
WORKSHOP PANEL

\section{$>$ NATIONAL SECURITY}

The workshop's second panel focused on national security. This panel was moderated by Gregory F. Treverton, a Professor of the Practice of International Relations and Spatial Sciences at the University of Southern California and the former Chair of the U.S. National Intelligence Council. Panelists included a representative from the U.K. Professional Head of Intelligence Assessment's COSMIC BAZAAR crowd forecasting platform; Matan Chorev, the Principal Deputy Director of Policy Planning Staff at the U.S.

Department of State; Joe Cyrulik, the Deputy Director at the Strategic Futures Group in the Office of the Director of National Intelligence/ National Intelligence Council; Stacie Pettyjohn, a Senior Fellow and the Director of the Defense Program at the Center for a New American Security; and Erin Sikorsky, a Visiting Fellow at Perry World House and the Director of the Center for Climate and Security.
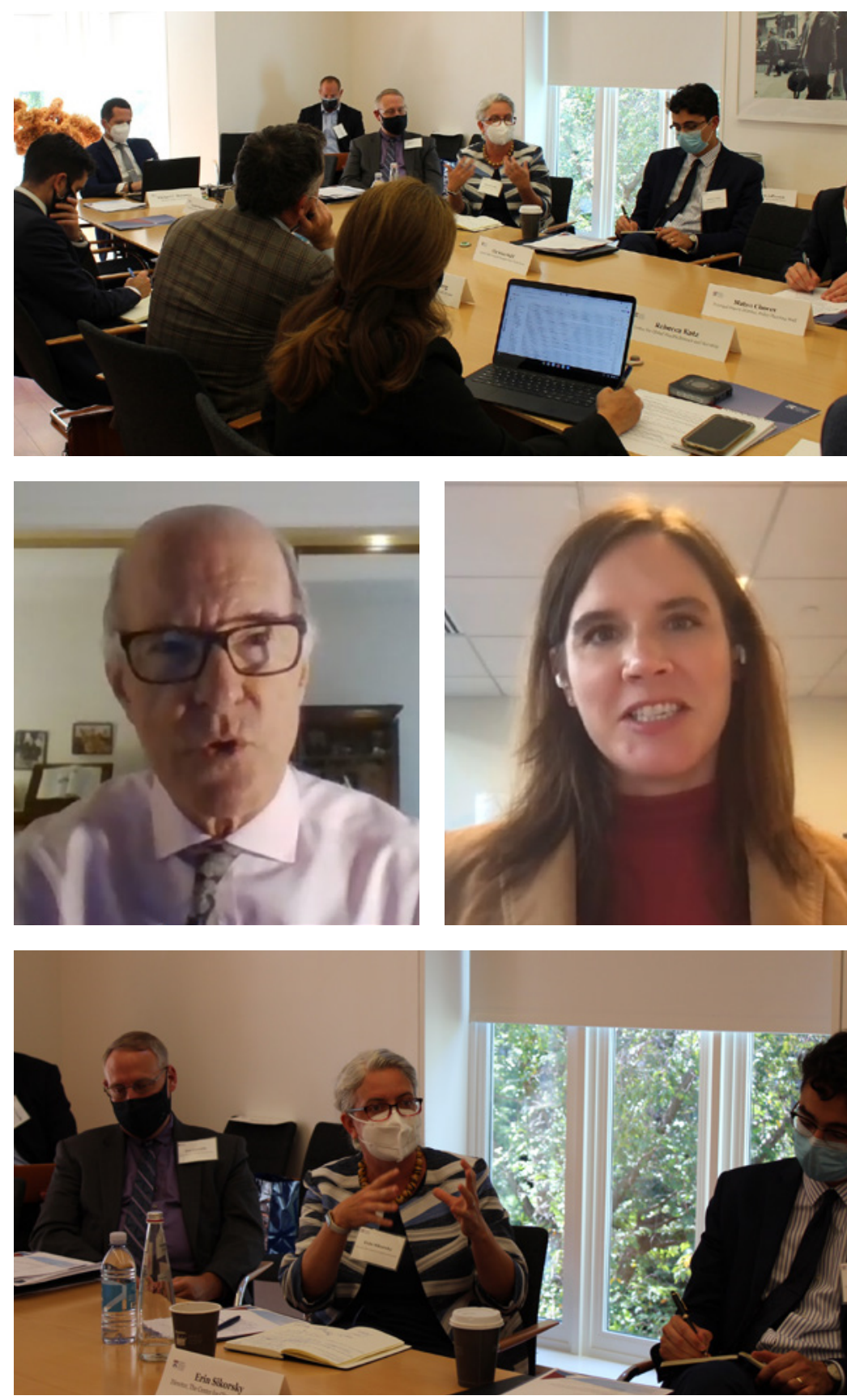

Participants in this panel included Erin Sikorsky, Visiting Fellow at Perry World House and Director of the Center for Climate and Security; Gregory F. Treverton, Professor of the Practice at the University of Southern California; and Stacie Pettyjohn, Senior Fellow and Director of the Defense Program at the Center for a New American Security. 


\section{"WE JUST EXPECTED WRONG"}

The surprisingly swift fall of Afghanistan to the Taliban in the months preceding the colloquium-and policymakers' apparent surprise at this result of rapid U.S. withdrawal — underlined the importance of accurate predictions to national security. Other failures to anticipate or adequately prepare for national security challenges define the past century of U.S. foreign policy; the COVID-19 pandemic, the September 11 attacks, and the attacks on Pearl Harbor are only some of the most prominent examples. Despite the great effort expended on intelligence analysis - and the many unsung and publicly unknown successes of the intelligence community-high vigilance clearly does not always lead to high forecast accuracy. In the famous words of game theorist Thomas Schelling, for example: "It is not true that we were caught napping at the time of Pearl Harbor. Rarely has a government been more expectant. We just expected wrong." 12

The big questions for national security scholars, practitioners, and forecasters are therefore: What are we "expecting wrong," and how can we learn to "expect right" more often? To answer the first question, Perry World House asked panelists in the pre-workshop survey, "What do you think is the single biggest risk the world is 'expecting wrong' today and why?" Their answers are in the figure below.

WHAT ARE WE "EXPECTING WRONG?”

Climate change

Effects of new technologies

Nuclear weapons

Global health emergencies

Rise of illiberalism

Unintended escalation

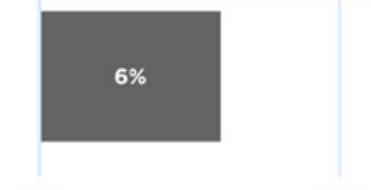

$0 \%$

$11 \%$

$11 \%$

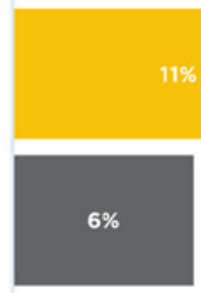

$11 \%$

$10 \%$
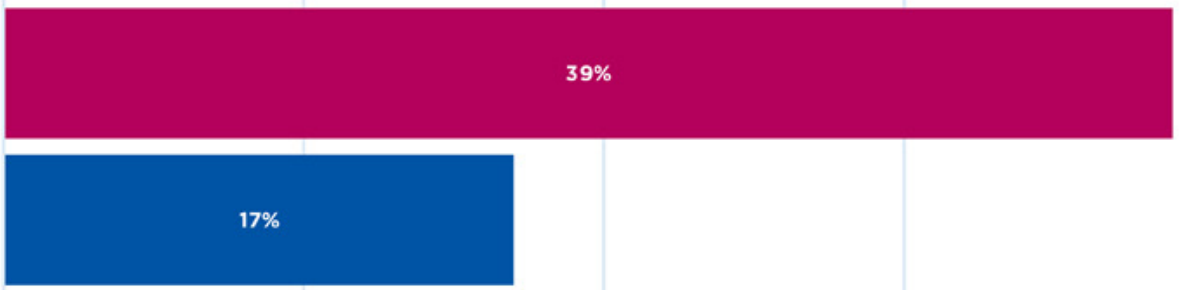

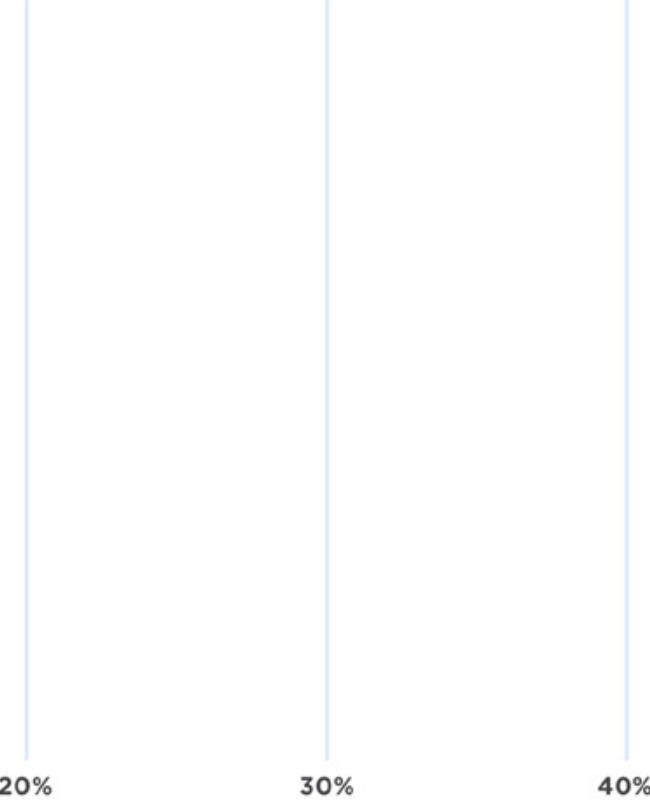

PERCENTAGE OF RESPONDENTS

Expecting Wrong: Responses to "What do you think is the single biggest risk the world is 'expecting wrong' today and why?" in Perry World House survey of workshop participants. 


\section{THE CLIMATE CHALLENGE}

Climate change dominated the answers as to what issues that the world is "expecting wrong," and it featured heavily in the conversation about national security forecasting. As climate change has become further exacerbated over time, climate challenges increasingly create national security challenges. Indeed, U.S. Secretary of Defense Lloyd Austin announced this year that the U.S. Department of Defense needs to take the global climate crisis into account in its war-gaming and exercise planning. ${ }^{13}$ Similarly, the Biden White House has also made it clear through executive order that climate and national security goals are intertwined. ${ }^{14}$ One panelist described climate issues not as an added threat, but rather a "threat multiplier." Climate change has a myriad of effects on national security planning and exacerbates situations on the air, ground, and sea. Climate not only has its effects in these competitive areas, but also affects state fragility, pandemic responses, or resource allocation. As the climate changes, strategists must alter their decisions and planning to adjust to the ever-changing nature of the environment where their decisions take effect.

Despite the urgency of the challenge and the sophisticated predictive models of climate scientists themselves, however, panelists argued that climate change is a missing factor in many national security forecasting exercises. One panelist noted that analysts cannot deal with "the 800-pound gorilla that is the U.S.'s effect on the climate." Furthermore, a panelist added that climate is a difficult aspect of forecasting because it is changing rapidly. Learning from climate science, and better integrating climate data into models of national security trends, will be key to better understanding the shape of the future.

\section{CAPTURING THE SPILLOVER EFFECTS OF RIGOROUS FORECASTING}

One major takeaway of the discussions was that the spillover effects of forecasting-stimulating debate, making disagreements more precise, framing questions as testable hypotheses, and encouraging more rigorous quantitative reasoning in government-may be as useful as the main aim of forecasting: making accurate predictions. A common theme in these discussions focused on how forecasting can stimulate debate and spur analysts to think rigorously about their predictions and how they convey information to their superiors in briefings; in other words, forecasting is for everyone.

Capturing these spillover effects, and making their value visible, will require better communication. One idea repeated among panelists was the use of storytelling and forecast narratives. "The story behind the numbers is as, if not more, important than the complexity of decisionmaking," one panelist said. "Value is not merely in the number produced, but what story goes on behind the scenes." The challenge of telling these stories, however, focused the discussions on the need for data literacy within branches of government. "We lack translators between the intelligence community and data scientists," one panelist said. "But we've gotten better now, the hiring process in the IC specifically asks for applicants' literacy with data." It's important to understand the limits of these applications, however, as some panelists pointed to policymakers' focus on over-hyped "big data" and other buzzwords.

Capturing these spillover effects may require not only a better recruitment strategy and greater numeracy in government, but also better design of forecasting aggregation platforms. Platforms that reward not just accuracy, but also engagement, can help to encourage analysts to keep forecasting even if they find their Brier scores discouraging. Facilitating engagement and rewarding open debate and "chattiness" on forecasting tools might have similar benefits.

13 Lloyd J. Austin, "Statement by Secretary of Defense Lloyd J. Austin III on Tackling the Climate Crisis at Home and Abroad," U.S. Department of Defense, January 27, 2021, https://www.defense.gov/News/Releases/Release/Article/2484504/statement-by-secretary-of-defense-lloyd-j-austin-iii-on-tackling-theclimate-cr/.

14 Joseph R. Biden, "Executive Order 14008 of January 27, 2021, Tackling the Climate Crisis at Home and Abroad," Federal Register, 86(19), January 27, 2021, https://www.regulations.gov/document/EPA-HQ-OPPT-2021-0202-0012. 


\section{ALLIES, ADVERSARIES, AND INTEGRATING FOREIGN AND DOMESTIC POLICY}

Much of the panel's discussions focused on the success of other nations in a variety of fora, both in using opensource intelligence and in implementing crowdsourced forecasting. Participants highlighted the U.K. COSMIC BAZAAR program as a model to emulate. Partly a product of the pandemic, the open-source nature of the forecasting platform allowed participants-from across the United Kingdom's bureaucracy—to work from home and facilitated a process that helped the United Kingdom continue to work during lockdown and implement innovative forecasting methods. As of the colloquium, there were 19,000 forecasts and counting on COSMIC BAZAAR.

In the United States, on the other hand, open-source analysis and forecasting implementation have lagged. Open-source forecasting has advantages. One point that our panelists touched on and that has been written about of late is a tendency for analysts to believe classified information over that which can be found publicly. ${ }^{15}$ Another is that such data has merely gone underutilized, as positions for open-source data procurement are relatively recent. A platform that allows both open-source and classified forecasts could be especially valuable.

Allied forecasts are important-as is interoperability between potential future allied forecasting platformsbut panelists also discussed how U.S. adversaries see the future. One panelist mentioned that Chinese officials do research on how to mimic U.S. war-gaming techniques. Another emphasized that Chinese intelligence agencies do extensive open-source research into the United States and do a better job of exploiting the public domain than other nations do. Understanding other countries' forecasting efforts could be one area for fruitful further research. After all, U.S.-China competition, according to surveyed experts, might be one of the biggest risks of all, as illustrated in the figure below.

\section{PROBABILITY OF U.S.-CHINA MILITARY CONFRONTATION}

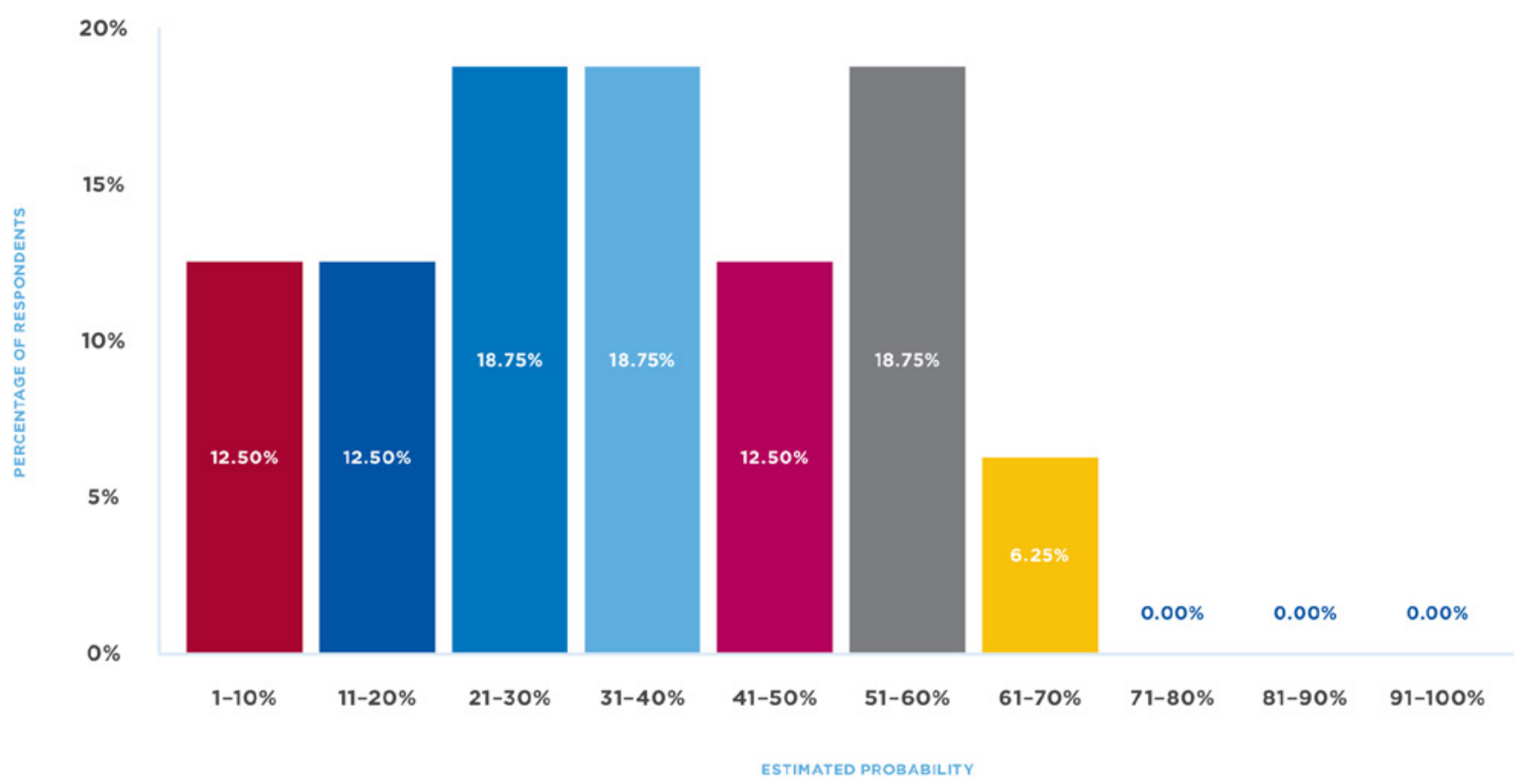

On China: Responses to "What is the likelihood of a military controntation between the United States and China that results in at least one death over the next five years?" in the Perry World House survey of workshop participants.

15 Cortney Weinbaum, “The Intelligence Community's Deadly Bias Toward Classified Sources," Defense One, April 9, 2021, https://www.defenseone.com/ ideas/2021/04/intelligence-communitys-deadly-bias-toward-classified-sources/173255/. 

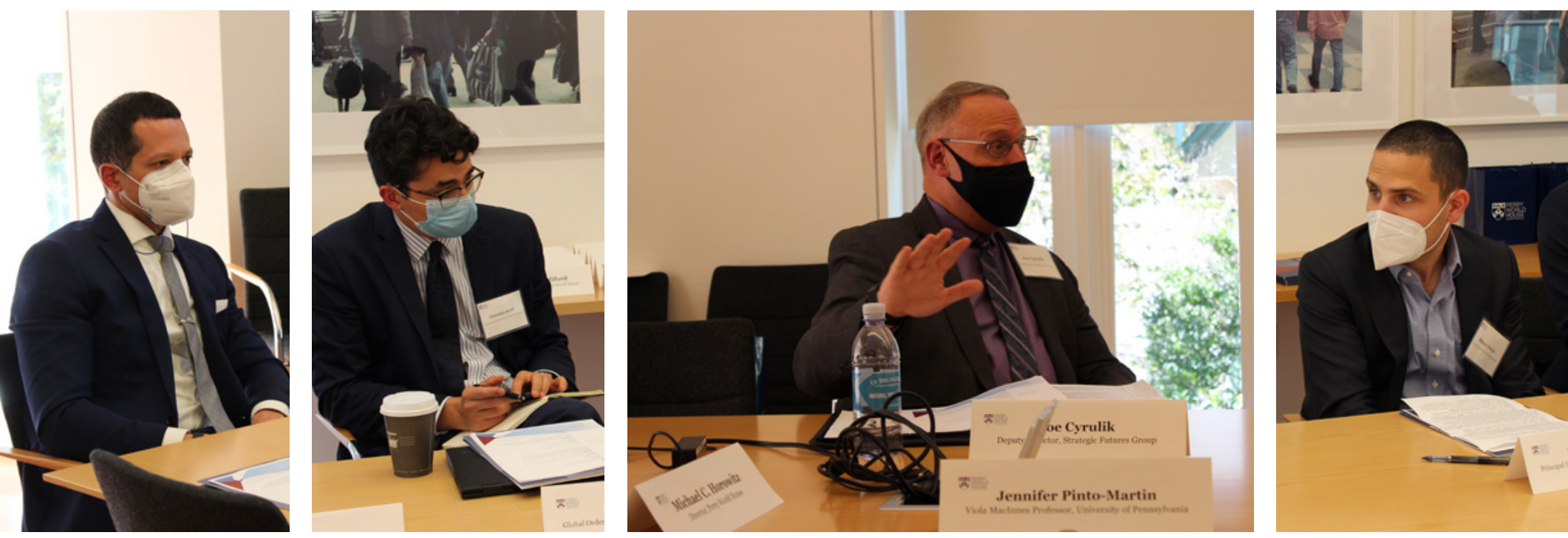

Perry World House's Michael C. Horowitz and Christian Ruhl; Joe Cyrulik, Deputy Director, Strategic Futures Group; and Matan Chorev, Principal Deputy Director, Policy Planning Staff, U.S. Department of State.

Lastly, in discussing probabilistic geopolitical forecasting, panelists discussed the difficulty of integrating forecasts on foreign issues with domestic political developments. The intelligence community is largely forbidden from analyzing the latter, despite the intertwined nature of these trends with one another. One panelist mused that, sometimes, U.S. domestic sentiment is one of the main factors shaping international political developments. The recent emphasis on "foreign policy for the middle class" implies a similar view of the domestic-international link. Indeed, forecasting methods could be useful to see what effects different international policies will have on one's own citizens. For example, how might different outcomes of trade negotiations affect manufacturing in small-town Ohio? Similarly, crowdsourced forecasting could be useful to display these kinds of inward-facing effects. One panelist underscored a chief issue in the tethering of domestic to foreign policy: "We need to ask, 'How do trends domestically affect positions abroad? Can domestic strengths create diplomatic strategy?" For instance, if the United States is emboldened to take on climate change domestically and can reliably spearhead climate policy, then the United States can utilize that in its diplomatic policy; using forecasting, the United States could see how its own domestic attitudes toward climate policy affect those of its allies and adversaries.

\section{??}

\section{QUESTIONS FOR FURTHER RESEARCH}

What are the biggest challenges to reimplementing a crowdsourced probabilistic forecasting platform in the U.S. intelligence community?

How can forecasts themselves and the spillover effects of forecasting be better communicated to policymakers?

How can advocates of new forecasting methods help to build demand among both producers and consumers of government forecasts? 

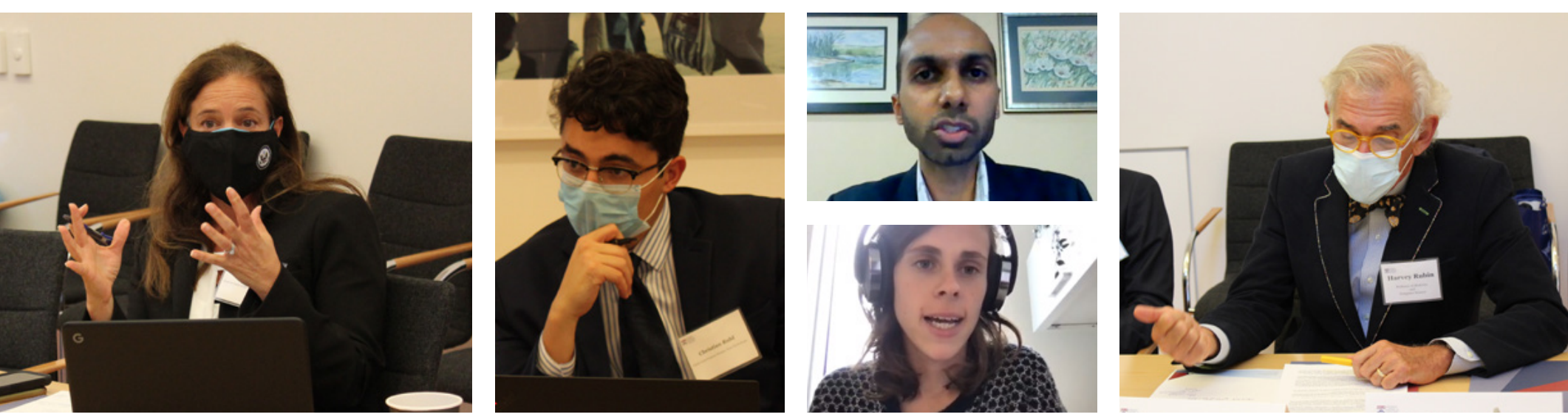

Rebecca Katz, Professor and Director, Center for Global Health Science and Security, Georgetown University; Perry World House's Christian Ruhl; Ridhwaan Suliman, Senior Researcher, South Africa's Council on Scientific and Industrial Research; Caroline Wagner, Assistant Professor of Bioengineering, McGill University; and Harvey Rubin, Professor of Medicine and Computer Science, University of Pennsylvania, take part in the panel discussion on Global Health.

economy panels, these participants were highly confident in the accuracy of their forecasts and felt that epidemiological models were sophisticated and accurate enough. After all, many public health experts had been expecting a global pandemic for many years. One panelist went so far as to say, "The most surprising thing about 2020 was that I became a dog person."

Not everyone is this confident. The Biden White House has taken some of the calls for better epidemic prediction to heart, through the establishment of an interagency National Center for Epidemic Forecasting and Outbreak Analytics and by "modernizing global early warning and trigger systems for scaling action to prevent, detect, respond to, and recover from emerging biological threats." ${ }^{18}$ This followed calls for "the contagion equivalent of the National Weather Service" for the U.S. government. ${ }^{19}$ New proposals for global pandemic monitoring services have grown very common, such as the establishment of a National Center for Epidemic Forecasting and Analytics, a Pandemic Early Warning System (akin to the Famine Early Warning System), or machine-learning models that use extant data to predict future pandemic outputs. ${ }^{20}$
In spite of these efforts at improving prediction and early warning, the global health panelists focused on a missing piece of the forecasting puzzle: communication and political will.

\section{FORECAST COMMUNICATION}

In part, the problem is that of communication. Experts make accurate forecasts, but struggle to communicate knowledge to the public and policymakers. Some panelists, for instance, mentioned travel restrictions put in place during the pandemic. They lamented that such restrictions are largely ineffective stopgaps against the spread of disease, but they were still put in place despite warnings from public health experts. Indeed, the WHO officially advises against restricting travel as a response to such crises. ${ }^{21}$ The WHO has three reasons behind this policy decision, as was outlined in the International Health Regulations (IHR) in 2005: (1) Travel and trade restrictions are believed to be largely ineffective at stemming the spread of a disease; (2) the WHO does not want to incentivize countries to withhold or otherwise alter their public health data lest other countries stop trading with them to stop pandemic spread; and (3) such measures make it harder to allocate resources and

18 The White House, "National Security Memorandum on United States Global Leadership to Strengthen the International COVID-19 Response and to Advance Global Health Security and Biological Preparedness," January 21, 2021, https://www.whitehouse.gov/briefing-room/statements-releases/2021/01/21/nationalsecurity-directive-united-states-global-leadership-to-strengthen-the-international-covid-19-response-and-to-advance-global-health-security-and-biologicalpreparedness.

19 Caitlin Rivers and Dylan George, "How to Forecast Outbreaks and Pandemics," Foreign Affairs, June 29, 2020, https://www.foreignaffairs.com/articles/unitedstates/2020-06-29/how-forecast-outbreaks-and-pandemics; Andrew S. Natsios, "Predicting the Next Pandemic," Foreign Affairs, July 14, 2020, https://www. foreignaffairs.com/articles/united-states/2020-07-14/predicting-next-pandemic.

20 The former two are cited in the above footnote, the latter: Gregory L. Watson, Di Xiong, Lu Zhang, et al., "Pandemic Velocity: Forecasting COVID-19 in the US with a Machine Learning \& Bayesian Time Series Compartmental Model," PLOS Computational Biology, 17(3): e1008837, 2021, https://doi.org/10.1371/journal. pcbi.1008837.

21 Tedros Adhanom Ghebreyesus, “WHO Director-General's Statement on IHR Emergency Committee on Novel Coronavirus (2019-NCoV),” World Health Organization, January 30,2020, https://www.who.int/director-general/speeches/detail/who-director-general-s-statement-on-ihr-emergency-committee-onnovel-coronavirus-(2019-ncov). 
WORDS OF ESTIMATIVE PROBABILITY: MORE BAD THAN GOOD?

Far worse

A bit more bad

Neutral

A bit more good

Far more good
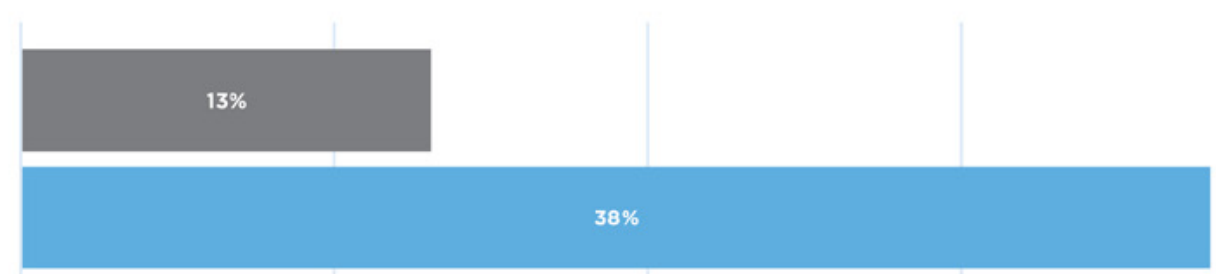

$19 \%$

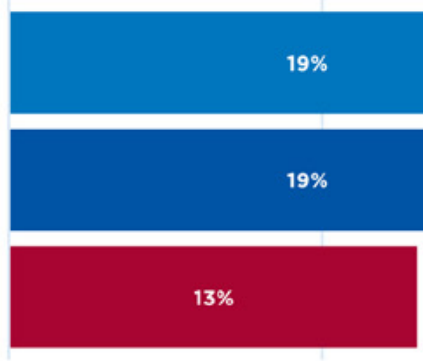

$10 \%$

$20 \%$

$30 \%$

$40 \%$

PERCENTAGE OF RESPONDENTS

Perry World House asked workshop participants to rate whether "words of estimative probability"

("likely," "fair chance," etc.) do more good or bad on balance compared with numerical probabilities.

assistance to underfunded or under-resourced places. ${ }^{22}$ Adding to this perspective, a panelist from the national security panel related that they had attended a wargaming exercise looking at the spread of influenza. During this scenario-planning exercise, officials largely favored closing borders and limiting travel—for political and optical reasons - but experts warned (and simulations showed) that such policies do not stop the spread of disease. Political incentives and global health incentives are clearly misaligned.

The implementation of international travel restrictions in the face of the COVID-19 pandemic underscores the divide between what public health experts know and model and what policy is ultimately executed. As Caroline Wagner mentioned in her written contribution to the colloquium: "Real-time tracking of biological markers from viral genomes to antibodies occurred to an unprecedented degree during the COVID-19 pandemic, yet efficiently using these data to guide public health responses remains an area for improvement." In this way, public health and climate issues suffer from a similar problem where experts' knowledge is often not acted on due to the misunderstandings of policymakers.
The fault is not entirely that of policymakers, but may stem in part from the careful culture of medical and scientific professions. Gregory Treverton described an interaction over epidemic forecasting in 1976 in his paper submitted prior to the colloquium:

Policy officials kept pressing the doctors for the likelihood of a major pandemic, but the doctors, professionally cautious to a fault, kept refusing to give one. One even said something like "I don't know, somewhere between zero and a hundred." Worse, his policy interlocutor interpreted that to be "50-50," which was far higher than any of the doctors privately assessed!

Even if forecasts are largely accurate, therefore, poor forecast communication and lack of political will can completely wipe out the benefits of accuracy. How we communicate forecasts remains a key area of improvement. Perry World House asked workshop participants to rate whether "words of estimative probability" ("likely," "fair chance," etc.) do more good or bad on balance compared with numerical probabilities. A majority felt that they do more bad. 


\section{PRIORITIZING PROBLEMS THROUGH BETTER FORECASTING}

Despite increased policy focus on improved epidemic forecasting and recent scientific advances that have given panelists good cause for confidence, global health preparedness and security remain low and underfunded across the globe (not just in the developing world); the Global Health Security Index found an average score of 40.2 out of their possible score of 100, with 116 highand middle-income countries failing to score about 50 out of $100 .^{23}$ This figure leads to the question: Why is global health systemically underfunded in both poor and rich countries?

Part of the explanation might concern not only the issues of risk communication and lack of political will, as noted above, but the difficulty of prioritizing policy problems. Pandemic preparedness does not intuitively feel like a pressing problem until a disease has already spread too widely. The urgent, as the aphorism teaches, crowds out the important, and the latest jobs report or terrorist attack dominates news cycles and policymakers' minds, while the looming risk of an even deadlier pandemic remains unaddressed. Here, too, widespread probabilistic forecasting might help. If policymakers are able to see "betting odds"-numbers quantified from the crowd's aggregated predictionson various issues, coupled with the magnitude of the forecasted threats, they might be able to make smarter bets. In this way, forecasting platforms encourage interdisciplinarity, and help policymakers rank the probabilities of events across issue areas, decreasing the neglect of key risks.

?

\section{QUESTIONS FOR FURTHER RESEARCH}

How can scientists and public health experts communicate more clearly and effectively with decision-makers?

Are failures to prepare for global health emergencies largely failures of prediction, or failures of political systems to respond to those predictions?

How can quantitative probabilities help to rank and prioritize problems that cross disciplinary boundaries?

23 The Global Health Security Index shines a light on holes in states' preparedness and capacity with regards to preventing a public health crisis: https://www.ghsindex.org/. 
KEYNOTE

\section{$>$ ELLEN JOHNSON SIRLEAF}

The second day of the Global Order Colloquium launched with a wideranging keynote and discussion with Ellen Johnson Sirleaf, the former President of Liberia, a Nobel Peace Prize Laureate, and the Co-Chair of the Independent Panel on Pandemic Preparedness and Response. Penn Nursing Dean Antonia M. Villarruel introduced President Sirleaf, noting that she was the first democratically elected female head of state in all of Africa, a staunch supporter of women's rights and human rights, and a speaker truly deserving of the title of being Perry World House "Distinguished Global Leader in Residence."

Beginning her speech, President Sirleaf noted that this was not her first time in Philadelphia. The last time she visited the City of Brotherly Love, Sirleaf spoke to an association of Liberian-Americans, criticized former Liberian President Samuel Doe's economic policy, and blamed the country's crumbling economy on the "many idiots in whose hands our nation's fate and progress have been placed," which resulted in her being charged with sedition and imprisoned once she returned to Liberia in $1985 .{ }^{24}$ No less outspoken this time, Sirleaf launched into a keynote and discussion with NPR's Deborah Amos on a variety of global issues, including vaccine inequity, economic development, women's rights, and the future of West Africa's role in the world.

\section{COVID-19 AND VACCINE INEQUITY}

As the Co-Chair of the Independent Panel for Pandemic Preparedness and Response, established by the World Health Organization, Sirleaf emphasized the necessity of global vaccine equity and vaccine

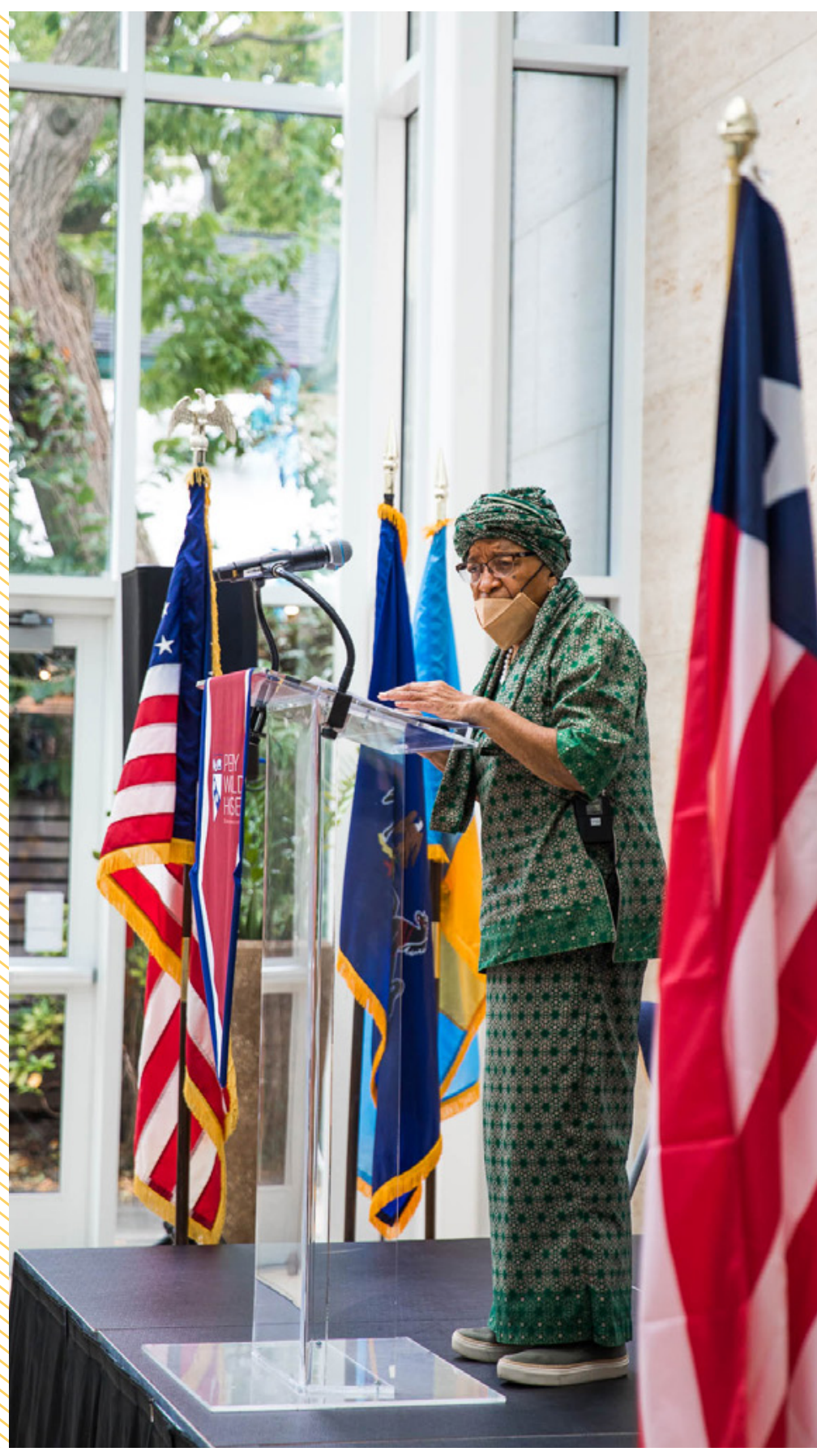

Former President of Liberia Ellen Johnson Sirleaf speaks at Perry World House. 
manufacturing in the Global South. Sirleaf's tenure during Liberia's Ebola crisis shaped her insights on pandemic response and preparedness, as well as her perspectives on global health inequality. Thus, Sirleaf argued, there is a need for corporations who own intellectual property to ease restrictions and allow technology transfers to developing countries.

Here was Sirleaf's crucial forecast for this colloquium on "How to See the Future": The future of the world will turn on the issue of vaccine inequity. As Sirleaf put it, "Nobody is safe until everyone is safe." Echoing the global health panelists' remarks on the ineffectiveness of border closures, Sirleaf noted that pandemics do not respect borders, and the Global North cannot ignore the South's public health needs. It is not enough, Sirleaf said, to have vaccines manufactured by the North and the Great Powers, and have them distributed via (sometimes unreliable) means to the rest of the world. Vaccine manufacturing itself, she argued, needs to be distributed more globally. Africa and Latin America are already pursuing this path, a potential road to truly ending the pandemic and helping to build more resilient global health systems.

\section{"Nobody is safe until everyone is safe."}

\section{— Ellen Johnson Sirleaf}

\section{SDGs, HUMAN RIGHTS, AND MORE}

Sirleaf also discussed the Sustainable Development Goals (SDGs), a collection of 17 interlinked global goals established in 2015 by the United Nations General Assembly designed to be a "blueprint to achieve a better and more sustainable future for all," which are currently off course to be achieved by the intended year of 2030 . "There's been some breakthroughs in the reduction of poverty, which is the number one goal," but she insisted that there are too many goals being left behind and that COVID-19 is a reminder "that whatever we do, wherever we are in this world, we are connected, we have an entwined chain of global existence."

Sirleaf also discussed women's rights and gender equality, and stressed that COVID-19 has destroyed livelihoods and pushed people back into extreme poverty, with women and girls suffering a disproportionate impact. She discussed the 1995 Fourth World Conference on Women, during which 189

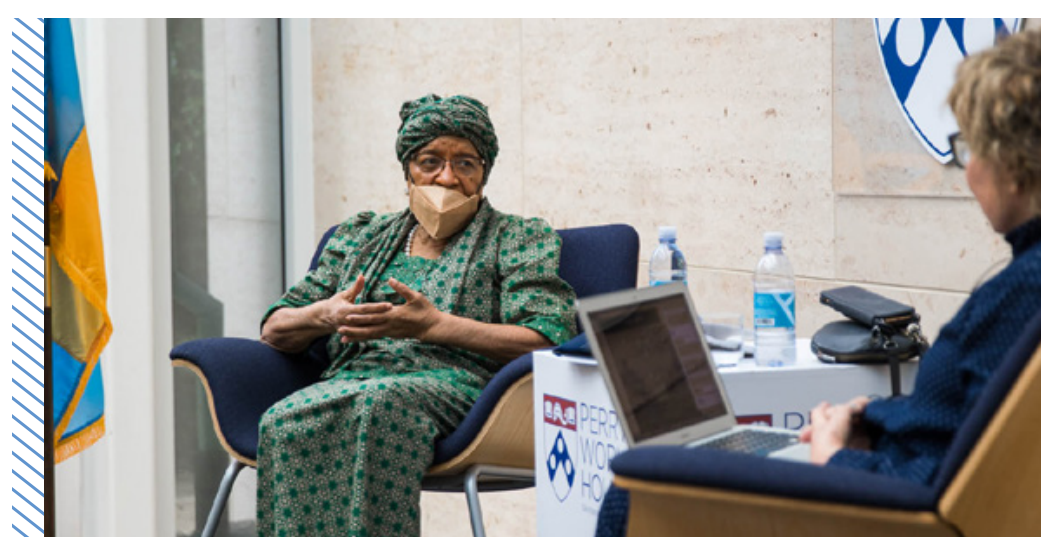

Ellen Johnson Sirleafin conversation with NPR's Deborah Amos.

countries adopted the Beijing Declaration and the Platform for Action. This agenda for women's empowerment includes goals to advance women's political leadership throughout the world. Sirleaf noted that 26 years later, women's equality is still lagging, including in the lack of women leaders around the globe.

Warning against nationalism, protectionism, and isolationism, Sirleaf urged students to be vigilant, cognizant of their power, and demand more from their national leaders; she spotlighted recent youth protests in Myanmar, Hong Kong, and Sudan. "You are the next generation," Sirleaf said. "All that we've talked about will be your responsibility. You will guide the destiny of the world. What you learn here will help, but after you get there, how will you use the talent you got here? How will you position yourself towards a goal? I'm now approaching my 83rd birthday. We must pass the torch on to you, young people, to have unwavering courage to make the world a better place, with equity for everyone."

\section{PENN AND WEST AFRICA}

Speaking to students, faculty, and staff at the university, Sirleaf also celebrated the relationship between Penn and Liberia. "This university's influence reaches the distant shores of West Africa," Sirleaf said. "Many of those who have come here to obtain their education and their professional skills have gone back and are rendering public and professional service well appreciated in our countries. And so, to the professors here, we urge you to continue to be the open house that you are to train those coming from different lands to enable them to go back and serve their countries." The president's role as a Distinguished Global Leader at Perry World House is helping to continue this legacy and expand Perry World House's ability to bring Penn to the world and the world to Penn. 
chronicled in his book to explain how the course of U.S. domestic politics reflected the nation's position on the international stage: "I was talking to [a group of Japanese business people] at the height of the Fire and Fury stuff in 2017. I thought they'd want to talk about North Korea. All they wanted to talk about was Charlottesville and Trump. And I realized that to them, an America that had kind of lost its mind was much more dangerous and scary than a foreign policy they didn't agree with or even a threat like North Korea."

Rhodes argued that although the U.S. position had already eroded away to some degree during the Obama years, the Trump White House's drastic changes to U.S. foreign policy (e.g., stepping back from the Joint Comprehensive Plan of Action with Iran) undercut America's position with its allies and adversaries. Rhodes identified the post-Cold War era of U.S. dominance in global affairs as the breeding place for the ideas that would feed into regimes that challenge the United States today. Specifically, a hyper-focus on technology and capital contributed to China's rise and continued Russian challenges to U.S. positions. U.S. technologies and their adoptions abroad have led to adversaries' ability to proliferate a stream of surveillance technologies that challenge U.S. values abroad. For instance, these technologies allow the Chinese government to survey Uyghurs and target opposition journalists.

\section{“BETTER THAN 50 PERCENT CHANCE”}

When an audience member asked, "What do you see as a probability that the U.S. will cease to be a liberal democracy by 2030?" Rhodes described a spectrum to autocracy and noted that the United States already lacks some attributes of a truly liberal democracy. Rhodes discussed what he framed as "minority rule" of the majority in the country, pointing especially to the Texas legislature. U.S. democracy, he argued, faces large challenges from within and without, and he emphasized that it is imperative for the United States to acknowledge its shortcomings and be more consistent on democracy itself.

In short: "Every election feels kind of existential," Rhodes said. "And so, to me, this is a less than 50 percent proposition when you look at the next decade" that the United States will remain a liberal democracy.

\section{ADVICE TO STUDENTS}

Students in the audience also seized the opportunity to gain key insights into their own futures as they seek to affect global policy. Asked by a viewer how students should think about what next steps they should take, Rhodes told students to follow the people they admire and to follow their passions. "I worked on issues I cared about," he said. "I met people and tried to learn from them. I said yes to a lot of extra, 'Hey, can you help out on this campaign?' And obviously I followed my passion to work for Barack Obama - and that was luck." But Rhodes underscored that a drive to fill one's résumé is not the right way to carve a path forward; he preferred working passionately on a project to doing things that look good on paper but don't help to shape the future in positive ways.

\title{
"What I felt very aware of the whole time I was in government is ... the American moment of hegemony had already crested before Obama came into office. ... It's kind of inevitable that other countries challenge American dominance, and Russia and China were already beginning to do that."
}

\author{
- Ben Rhodes
}




\section{NEXT STEPS}

\section{> POLICY AND RESEARCH RECOMMENDATIONS}

The colloquium advanced key debates on forecastinghow can forecasting methods be improved, how can crowdsourced forecasting find a more permanent governmental home, how can various methods become complementary not competitive, how can good forecasts be communicated to policymakers, and more. This section outlines key recommendations for scholars and policymakers and describes Perry World House's continuing and upcoming work on forecasting.

The colloquium made public an exciting new development in forecasting: The National Intelligence Council is taking the insights of decades of academic research on forecasting and using it to build a new crowdsourced platform. Other government initiatives are also starting up-which is important because there's no time to waste. The developments in the U.S. government are promising, but there is now an implementation challenge. A crowdsourced forecasting platform will only be successful if analysts regularly engage with it and if policymakers take its outputs seriously. Moreover, as the colloquium showed, making the new NIC initiative complementary to, not competitive with, other forecasting tools and methods like war-gaming will require careful research and smart implementation strategies.
To this end, the following section outlines key recommendations with three broad aims:

1. Increasing bureaucratic demand for forecasting: Crowdsourced forecasting only succeeds when the crowd forecasts, and when analysts and policymakers alike view probabilistic forecasts as a valuable tool, not an obligation.

\section{Learning from allies-and} adversaries: The United Kingdom's COSMIC BAZAAR program provides a model for success for other nations, including the United States. Innovation in forecasting, moreover, could be a key advantage in great power competition.

\section{A roadmap to permanent}

forecasting implementation: In order to succeed, a new forecasting platform must be implemented strategically, such that it becomes a permanentand inextricable-feature of the intelligence and policy processes. 


\section{INCREASING BUREAUCRATIC DEMAND FOR FORECASTING}

Crowdsourced forecasting only succeeds when the crowd forecasts. Participants familiar with previous intelligence community forecasting initiatives, like the Intelligence Community Prediction Market (ICPM), noted that analysts often saw the ICPM as either a "toy" or an "obligation." Without the broad participation of analysts in a new forecasting aggregation platform, however, the forecasts will not have the power that they otherwise would-power supported by large numbers and by a diversity of forecasters. Therefore, a new forecasting tool should be easy to use, widely advertised, and-a word not always associated with the intelligence community-fun. Similarly, some policymakers remain skeptical of the use of probabilistic forecasting, and a few expressed their reservations at the colloquium. Continuing to educate and build demand for forecasting among forecast consumers will be as critical as creating a broad base of forecast producers. These goals can be achieved through messaging and policies that emphasize how its organizational and cultural spillover effects go beyond merely the accuracy of forecasts themselves and how forecasting is valuable, fun, and a way to advance meritocratically.

Broad messaging on the new forecasting initiative should emphasize a simple truth: Forecasting is for everyone. First, the improved accuracy of probabilistic forecasts helps everyone involved in the decision-making process better understand and prioritize risks and policy solutions. Second, crowdsourced forecasts provide a valuable complement to other methods across disciplines, as every panel at the workshop acknowledged-war-gaming and scenario-planning, for example, could be improved and modified as forecasts are updated. Third, forecasting can be a vehicle for education and training-several panelists pointed to a lack of basic statistical numeracy in governments across the world. Finally, forecasts generate debate, the open exchange of ideas, and rigorous testing of these ideas. A forecasting platform, therefore, improves the policy process in broad and valuable ways.

Relatedly, the value proposition to managers and policymakers should focus on the spillover effects of forecasting, and the design of the new forecasting platform should emphasize that the value of forecasters is in more than their Brier scores. Several private forecasting initiatives, panelists pointed out, have found that would-be forecasters are easily discouraged when their forecasts are wrong. Perry World House interviews with policymakers, and the discussions at this colloquium, have highlighted a similar issue. Incentivizing participation over performance in leaderboards and scores, rewarding "chattiness" or comments on forecasts, and encouraging debate will all help to keep forecasters engaged with the platform, even if they are not at the top of Brier score rankings.

At a moment of levity in the discussions, one panelist noted that participants in COSMIC BAZAAR had been forecasting on the outcome of the popular baking competition show The Great British Bakeoff, alongside serious questions about geopolitics and military capabilities. This comment, however, holds an important insight-forecasting should be fun. Few bureaucrats view forecasting as their primary responsibility, so participants should look forward to their time as part-time forecasters. A new platform should therefore be easy to use, and its outputs should be easy to export and incorporate into intelligence products. Ease of use, simplicity, and fun should be no afterthoughts; insights gained in social media research can help to inform the design and communication strategy for future forecasting initiatives.

\section{LEARNING FROM ALLIES- AND ADVERSARIES}

A recurring question during the colloquium was how forecasting can be made more global, and what the United States can learn from both allies and adversaries. Though the United States was a first mover on forecasting and prediction markets in government, for example, the success of the United Kingdom's COSMIC BAZAAR program should be a model for future implementation, and the beginning of a conversation on working better together with allies. Moreover, the question of how to forecast globally on transnational threats-climate risks, global health, and more-needs greater academic attention.

Only truly global data collection and greater multilateral collaboration can help improve forecasting, especially on global public health. Better data are one key to improved global health forecasting, lest scientists perform "elegant math on crappy data," in the words of one epidemiologist. ${ }^{25}$ In some cases, collecting better data requires not high-tech interventions, but simple capacitybuilding for on-the-ground data collection. As one recent Nature news feature showed, infectious disease monitoring in Liberia suffered simply "because there were no sample tubes to collect blood." ${ }^{26}$ States, especially but not exclusively authoritarian ones like Russia,

\footnotetext{
25 Amy Maxmen, "Has COVID Taught Us Anything About Pandemic Preparedness?” Nature, August 13, 2021, https://www.nature.com/articles/d41586-02102217-y.

26 Ibid.
} 
moreover, are still proving to be some of the biggest obstacles to truly global health monitoring and forecasting, sharing few data, bad data, or distorted data.

To better analyze these data and make accurate predictions-on global health and beyond - the United States and other countries should look to the success of COSMIC BAZAAR. As an unclassified governmentwide initiative, the program brings together a diversity of voices across the United Kingdom's range of public servants. The design of this platform-both its features and its bugs - should be the subject of U.S.-U.K. discussions on forecasting, and the two countries can work closely together to improve their forecasts, the incentives offered to forecasters, and the value proposition made to policymakers. Sharing best practices for forecasting could also help to start a wider conversation on sharing intelligence, standardizing data, and more.

Allies can learn much from each other, but adversaries also figure into the conversation on forecasting implementation. The ability to better see the future, through crowdsourced methods paired with traditional analysis, will be a competitive advantage in great power competition, and better forecasts about an adversary's actions may help to lower uncertainty in planning for conflict. Future research on China's approach to forecasting could prove invaluable both in understanding forecasting innovations and in understanding the Chinese state itself.

\section{ROADMAPS TO PERMANENT FORECASTING IMPLEMENTATION}

Many challenges remain in bridging the gap between what we know about how to make more accurate predictions and what governments are doing with this knowledge. To help governments better navigate this challenge of translation and implementation, academia and think tanks can help to create roadmaps for forecasting platforms. Now is a pivotal time for innovation in forecasting, and thought leadership on this issue will be crucial in helping busy government officials make important strategic decisions about forecasting. A number of open questions remain. What is the best communications strategy for forecasts? How can forecasts be most seamlessly integrated into the policy process? How can engagement with forecasts be rewarded? What do policymakers find most useful?

On the last question, there are numerous smaller questions on communication. For example, many panelists emphasized the value of disagreement and understanding the distribution of forecasts. A new forecasting platform should include the option to expand the single number of a crowd forecast into a probability distribution-privately owned forecasting platforms already include such features. To demonstrate, the graph below unpacks the distribution of experts' opinions on the likelihood that emissions will be reduced enough by 2030 to keep warming below 1.5 degrees. From this graph, it becomes clear that not only did most of the survey's respondents think that sufficient emissions reductions are unlikely by 2030 , but none of those who answered the survey thought the chance was better than even that emissions would be reduced enough. Such information could be crucial to policymakers, either to identify expert consensus or groupthink. 
PROBABILITY OF EMISSIONS REDUCTION FOR SUB-1.5 ${ }^{\circ}$ WARMING BY 2030

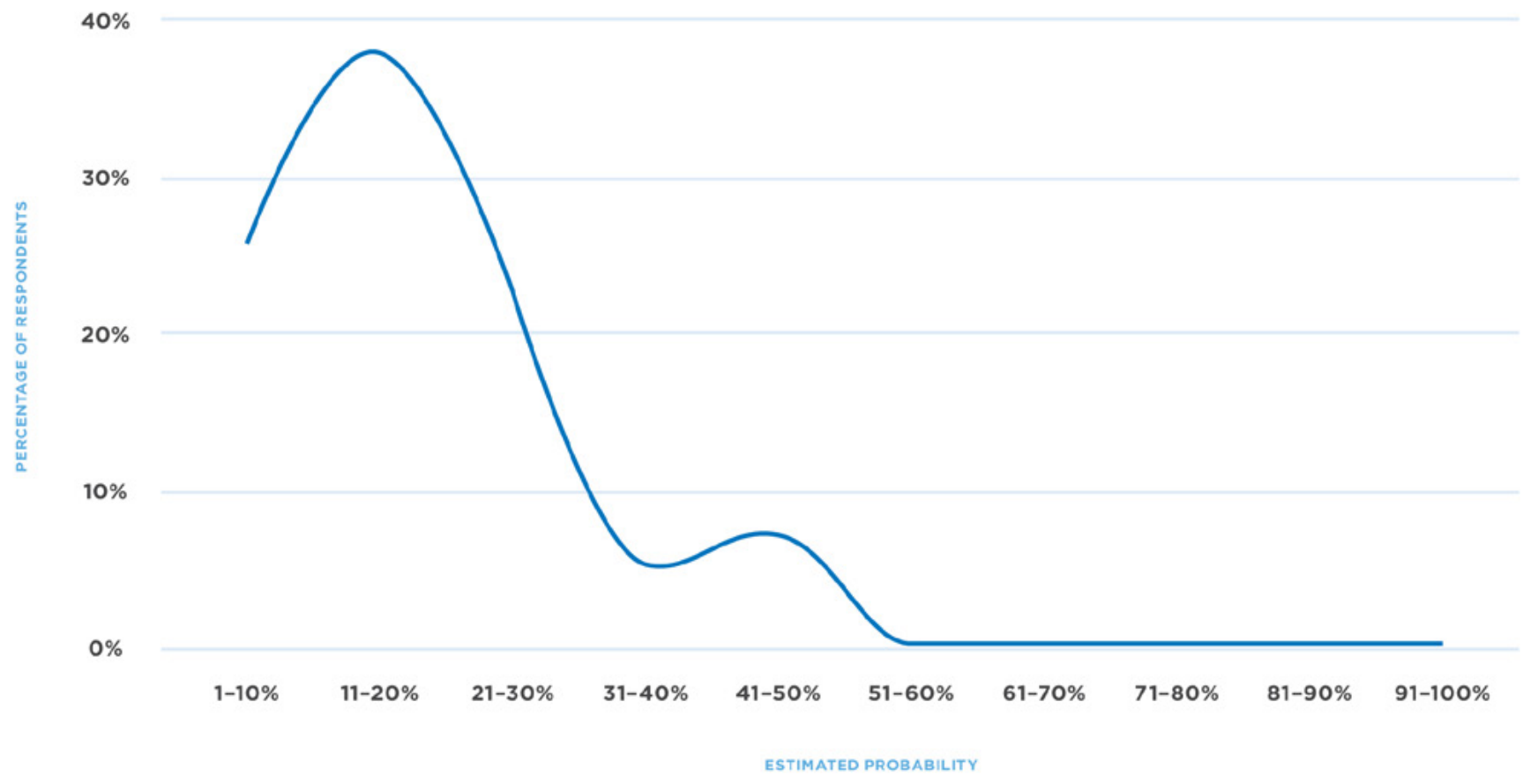

The distribution of experts' opinions on the likelihood that emissions will be reduced enough by 2030 to keep warming below 1.5 degrees.

\section{$>$ CONCLUSION}

Now is an exciting time for forecasting, and Perry World House will continue its work in this space. With the support of Open Philanthropy, Perry World House will continue interviewing policymakers to understand how to solve the remaining implementation challenges and questions raised during the colloquium-such as, how can forecasts help to integrate foreign and domestic policy, how can forecasts be better communicated, how can they account for policymaker interventions, and more.
Perry World House's working group, Predictive Intelligence Assessment Methods (PRIAM), will also build on the conversations of the colloquium and continue to encourage scholars, practitioners, and government officials to openly exchange their views about forecasting and global policy. An upcoming Perry World House report, based on recent research, will provide a roadmap for implementation and a clear guide for policymakers to make the most of this moment.

In the meantime, the list below provides ample reading on forecasting and the future of the world, with the experts' recommendations for readings on forecasting in global health, the global economy, and national security. 


\section{> WHAT THE EXPERTS ARE READING}

- Appelbaum, Binyamin. The Economists' Hour: False Prophets, Free Markets, and the Fracture of Society. Little, Brown, 2019.

- Cunzeman, Kara C., and Robin Dickey. "Strategic Foresight: Addressing Uncertainty in Long-Term Strategic Planning." Center for Space Policy and Strategy, Space Agenda, 2021. Accessed October 8, 2021. https://aerospace.org/paper/strategic-foresightaddressing-uncertainty-long-term-strategic-planning.

- Clements, Michael P., and Ana Beatriz Galvão. "Macroeconomic Forecasting With Mixed-Frequency Data: Forecasting Output Growth in the United States." Journal of Business \& Economic Statistics, 26(4): 546-554, October 2008. https://doi. org/10.1198/073500108000000015.

- Economist Intelligence Unit. "What Next for Vaccine Diplomacy?” EIU, 2021, https://www.eiu.com/n/ campaigns/q2-global-forecast-2021/.

- Horowitz, Michael C., Julia Ciocca, Lauren Kahn, and Christian Ruhl. "Keeping Score-A New Approach to Geopolitical Forecasting." Perry World House, February 2021, https://global.upenn.edu/sites/default/ files/perry-world-house/Keeping\%20Score\%20 Forecasting\%20White\%20Paper.pdf.

- Lewis, Michael. Moneyball: The Art of Winning an Unfair Game. W. W. Norton \& Company, 2004.

- Makridakis, Spyros G., Spyros Makridakis, and Steven C. Wheelwright. Forecasting: Methods and Applications. Wiley, 1978.

- Mellers, Barbara, Lyle Ungar, Jonathan Baron, et al. "Psychological Strategies for Winning a Geopolitical Forecasting Tournament." Psychological Science, 25(5): 1106-1115, May 1, 2014. https://doi. org/10.1177/0956797614524255.

- Mellers, Barbara, Eric Stone, Terry Murray, et al. "Identifying and Cultivating Superforecasters as a Method of Improving Probabilistic Predictions." Perspectives on Psychological Science, 10(3): 267-281, May 1, 2015. https://doi.org/10.1177/1745691615577794.

- Neustadt, Richard E., and Ernest R. May. Thinking in
Time: The Uses of History for Decision-Makers. Free Press, 1986.

- Oppenheimer, Michael F. Pivotal Countries, Alternate Futures: Using Scenarios to Manage American Strategy. Oxford University Press, 2015.

- Pettyjohn, Stacie L., and David A. Shlapak. "Gaming the System: Obstacles to Reinvigorating Defense Wargaming." War on the Rocks, February 18, 2016. https://warontherocks.com/2016/02/gaming-thesystem-obstacles-to-reinvigorating-defensewargaming\%.

- Saffo, Paul. "Six Rules for Effective Forecasting." Harvard Business Review, July 1, 2007. https://hbr. org/2007/07/six-rules-for-effective-forecasting.

- Schwartz, Peter. The Art of the Long View: Paths to Strategic Insight for Yourself and Your Company. Currency Doubleday, 1996.

- Scoblic, J. Peter, and Philip E. Tetlock. “A Better Crystal Ball.” Foreign Affairs, October 16, 2020. https://www.foreignaffairs.com/articles/unitedstates/2020-10-13/better-crystal-ball.

- Silver, Nate. The Signal and the Noise: Why So Many Predictions Fail_but Some Don't. Penguin, 2015.

- Taleb, Nassim Nicholas. The Black Swan: The Impact of the Highly Improbable. Random House Publishing Group, 2007.

- Tetlock, Philip E. Expert Political Judgment: How Good Is It? How Can We Know? Princeton University Press, 2017.

- Tetlock, Philip E., and Dan Gardner. Superforecasting: The Art and Science of Prediction. Crown, 2015.

- Wright, Jonathan H. "Some Observations on Forecasting and Policy." International Journal of Forecasting, 35(3): 1186-1192, 2019. 


\section{घU PERRY \\ WORLD
HOUSE}

UNIVERSITY OF PENNSYLVANIA I PERRY WORLD HOUSE

3803 LOCUST WALK, PHILADELPHIA, PA 19104

215.573 .5730

@PERRYWORLDHOUSE

FACEBOOK.COM/PERRYWORLDHOUSE

GLOBAL.UPENN.EDU/PERRYWORLDHOUSE 